\title{
Viabilidade econômica da produção de novilhas leiteiras a pasto em sistema de integração lavoura-pecuária
}

\author{
Hernani Alves da Silva(1), Anibal de Moraes(1), Paulo César de Faccio Carvalho( ${ }^{(2)}$, Adriel Ferreira da Fonseca(3), \\ Vânia Di Addario Guimarães ${ }^{(1)}$, Alda Lúcia Gomes Monteiro(1) e Claudete Reisdorfer Lang ${ }^{(1)}$
}

\begin{abstract}
(1)Universidade Federal do Paraná, Departamento de Fitotecnia e Fitossanitarismo, Setor de Ciências Agrárias, Rua dos Funcionários, no 1.540, CEP 80035-050 Curitiba, PR. E-mail: hernanialves@emater.pr.gov.br, anibalm@ufpr.br, vania.di@ufpr.br, alda.lgm@ufpr.br, langc@ufpr.br (2)Universidade Federal do Rio Grande do Sul, Departamento de Plantas Forrageiras e Agrometeorologia, Avenida Bento Gonçalves, no 7.712, Caixa Postal 776, CEP 91501-970 Porto Alegre, RS. E-mail: paulocfc@ufrgs.br (3)Universidade Estadual de Ponta Grossa, Departamento de Ciência do Solo e Engenharia Agrícola, Avenida General Carlos Cavalcanti, no 4.748, Campus Uvaranas, CEP 84030-900 Ponta Grossa, PR. E-mail: adriel@uepg.br
\end{abstract}

Resumo - O objetivo deste trabalho foi avaliar a rentabilidade do sistema de integração lavoura-pecuária (ILP), em comparação ao cultivo de cereais de inverno e de plantas de cobertura para o plantio direto de soja e milho no verão. Foram comparados dados simulados de sistema agrícola tradicional com produção de grãos de milho e soja, no verão, e cultivo de trigo e plantas de cobertura do solo, no inverno; e dados de um trabalho publicado em que foram avaliadas combinações de pastagens (diversificadas ou puras) e categorias de animais (leves ou pesados), com produção de grãos de milho e soja, no verão, e pastejo no inverno. A análise econômica foi realizada com base nos resultados experimentais e simulada para uma propriedade de 100 ha. A ILP com recria de novilhas leiteiras em pastagens anuais de inverno, em substituição ao sistema convencional com cultivo de cereais de inverno e plantas de cobertura de solo para o plantio direto, é a alternativa mais rentável aos produtores.

Termos para indexação: agricultura conservacionista, análise econômica, pastagens anuais de inverno, recria de novilhas, sistema integrado de produção.

\section{Economic viability of dairy heifer production on pasture in crop-livestock integration system}

\begin{abstract}
The objective of this work was to evaluate the profitability of the integrated crop-livestock (ICL) system in comparison to the cultivation of winter cereals and cover crops for soybean and maize cropped under no-tillage in the summer. The following were compared: simulated data from a conventional agricultural system with production of maize and soybean grains in the summer and cultivation of wheat and ground cover plants in the winter; and data from a published work in which combinations of pastures (diversified or pure) and animal categories (light or heavy) were evaluated in a system with the production of maize and soybean in the summer and grazing during the winter. Economic analysis was carried out based on previous experimental results and simulated for a 100-ha property. ICL with rearing of dairy heifers in winter annual grazing, as a replacement to winter cereal crops and ground cover crops for no-tillage, is the most profitable alternative for producers.
\end{abstract}

Index terms: conservationist agriculture, economic analysis, annual winter pastures, heifer rearing, integrated production system.

\section{Introdução}

A principal bacia leiteira do Brasil situa-se no Município de Castro, na região dos Campos Gerais do Paraná (Instituto Brasileiro de Geografia e Estatística, 2012). Nesta região, $70 \%$ do leite é produzido em sistemas com confinamento total ou semiconfinamento, que apresentam custos totais relativamente altos (Silva et al., 2008). Consequentemente, alternativas para a redução dos custos de produção são necessárias, tendo em vista a possibilidade de redução na margem líquida do produtor nesses sistemas.

No ano agrícola de 2009/2010, dos 702.000 ha da região dos Campos Gerais cultivados no verão, apenas 27\% (190.000 ha) foi cultivado com cereais de inverno, principalmente o trigo (Triticum aestivum L.) (Paraná, 2010). O restante da área foi cultivada com gramíneas anuais de inverno - sobretudo aveia-preta 
(Avena strigosa Schreb) e azevém anual (Lollium multiflorum L.), consorciadas ou não com leguminosas, como a ervilhaca (Vicia sativa L.) ou as brássicas [nabo-forrageiro (Raphanus sativus L.)] -, ou deixadas em pousio (Paraná, 2010). Este cenário indica a subutilização de áreas, e, portanto, o adequado uso e manejo no sistema de integração lavoura-pecuária (ILP) pode representar oportunidade para intensificar o uso econômico das propriedades, com a produção de novilhas de reposição à base de pastagens anuais de inverno nas áreas cultivadas com grãos durante o verão (Balbinot Junior et al., 2009).

O elevado potencial de produção de carne e leite em sistema de ILP tem sido descrito em diversos trabalhos. Restle et al. (2000), Marchezan et al. (2002), Assmann et al. (2004) e Silva et al. (2008) verificaram que a ILP é uma estratégia de diversificação agropecuária que pode trazer benefícios técnicos, econômicos e biológicos, pois implica na diversificação das fontes de recursos, na diminuição dos riscos de queda de produção (Lazzarotto et al., 2010) e na redução dos impactos ambientais negativos (Cerri et al., 2010). No entanto, são necessários mais estudos que evidenciem as vantagens econômicas desse sistema, para fundamentar e promover maior adoção por parte dos produtores (Fontaneli et al., 2000). O cultivo de pastagens anuais durante o inverno, no Paraná, é uma alternativa ao cultivo de cereais de inverno. Contudo, cabe destacar que o sistema de ILP tende a ser mais complexo, uma vez que exige do produtor rural um conjunto maior de conhecimentos técnicos e mercadológicos, que estão relacionados às atividades agrícolas e de pecuária (Lazzarotto et al., 2010).

O objetivo deste trabalho foi avaliar a rentabilidade do sistema de ILP, em comparação ao cultivo de cereais de inverno e de plantas de cobertura para o plantio direto de soja e milho no verão.

\section{Material e Métodos}

Os dados experimentais foram obtidos de um trabalho publicado sobre sistemas de ILP, conduzido em 17 ha, na unidade de produção de novilhas da Cooperativa Agropecuária Castrolanda, no Município de Castro, PR, nos anos agrícolas de 2008/2009 e 2009/2010 (Silva et al., 2011). A área está localizada na região fisiográfica denominada Primeiro Planalto Paranaense
( $24^{\circ} 47^{\prime} 28^{\prime \prime} \mathrm{S}$ e $50^{\circ} 00^{\prime} 25^{\prime \prime} \mathrm{W}$, a $1.005 \mathrm{~m}$ de altitude). O clima da região, segundo Köppen, é subtropical úmido, do tipo $\mathrm{Cfb}$ (Cartas climáticas do Estado do Paraná, 1994). No sistema de ILP, foram avaliados quatro tratamentos, que consistiram de combinações de pastagens puras ou diversificadas e categorias de animais leves ou pesados, com pastejo no inverno e com produção de grãos de milho e soja, no verão (Silva et al., 2011).

Os dados obtidos para o sistema de ILP foram comparados aos de um sistema agrícola tradicional simulado. Para as análises econômicas, foram simulados resultados para uma área de 100 ha, na qual utilizouse o sistema agrícola tradicional, com os cultivos de trigo e aveia-preta no inverno, e de soja e milho no verão. Foram determinados indicadores técnicos para os dois sistemas. A caracterização dos sistemas de produção simulados e os indicadores técnicos usados para a análise econômica estão apresentados na Tabela 1. As pastagens foram conduzidas de forma integrada à produção agrícola, tendo-se observado calendários e proporções de áreas conforme Carvalho et al. (2005). No experimento com o sistema de ILP, utilizou-se o delineamento experimental de blocos inteiramente casualizados, com três repetições e quatro tratamentos. Os tratamentos consistiram de: animais leves $(192 \pm 40,9 \mathrm{~kg}$ em média de peso vivo e idade média de 9,4 $\pm 2,31$ meses) em pastagem diversificada composta de azevém anual, aveia-preta, trevo-branco (Trifolium repens L.) e trevo-vermelho (Trifolium pratense L.) (ALD); animais pesados ( $278 \pm 41,2 \mathrm{~kg}$ em média de peso vivo e idade média de 19,6 $\pm 2,47$ meses) em pastagem diversificada (APD); animais leves em pastagem pura composta de azevém anual (ALP); e animais pesados em pastagem pura de azevém anual (APP) (Silva et al., 2011).

No ano agrícola de 2008/2009, após a pastagem anual de inverno, foi implantada a cultura da soja [Glycine $\max ($ L.) Merril], e, na safra de 2009/2010, a cultura do milho (Zea mays L.). Em outubro de 2008, os animais saíram da área experimental, o que totalizou 89 dias de pastejo. Na sequência, procedeu-se à dessecação da fitomassa de pastagem com o herbicida glifosate. Aos 33 dias após a dessecação, foi realizada a semeadura da soja (cultivar CD 205), tendo-se utilizado espaçamento entrelinhas de $40 \mathrm{~cm}$ e fertilização no sulco de semeadura de $300 \mathrm{~kg} \mathrm{ha}^{-1}$ da fórmula 00-20-20 (N- $\left.\mathrm{P}_{2} \mathrm{O}_{5}-\mathrm{K}_{2} \mathrm{O}\right)$. Para a avaliação do rendimento de grãos de soja, foram 
colhidas manualmente quatro linhas de 4,0 m por cada parcela (área útil de 7,2 $\mathrm{m}^{2}$ ), nas situações com e sem pastejo. Após trilhados e limpos, foi determinado o teor de umidade dos grãos, com correção para $130 \mathrm{~g} \mathrm{~kg}^{-1}$ (Silva et al., 2011).

Em 2009, os animais foram retirados da área experimental em 5 de outubro, o que totalizou 88 dias de pastejo. Foi feita a dessecação da pastagem e, aos 25 dias após a retirada dos animais, procedeu-se a semeadura do milho (híbrido simples modificado ATL 200), tendo-se utilizado espaçamento entrelinhas de $80 \mathrm{~cm}$. A colheita foi realizada em abril de 2010 , para a determinação do rendimento de grãos de milho, mediante a colheita manual de quatro linhas centrais de 4,0 $\mathrm{m}$ por cada parcela (área útil de $12,8 \mathrm{~m}^{2}$ ), nas situações com e sem pastejo (Silva et al., 2011).

Para a análise econômica dos sistemas de produção, foi utilizada a planilha eletrônica Microsoft Excel Modelagem de Propriedade no Paraná - soja, milho, trigo e aveia (Guimarães et al., 2000). Os preços de venda dos produtos, nos últimos cinco anos, foram obtidos junto à Secretaria da Agricultura e do
Abastecimento do Paraná/Departamento de Economia Rural (Paraná, 2010), e foram deflacionados pelo IGP-DI (Índice Geral de Preços - Disponibilidade Interna) da Fundação Getúlio Vargas, para abril de 2010. Já os preços dos insumos e dos serviços, foram obtidos junto à Cooperativa Agropecuária Castrolanda, Castro, PR, pela sua importante atuação no mercado regional. A partir dessa análise, calculou-se o custo total de produção para as lavouras, em $\mathrm{R} \$ \mathrm{ha}^{-1}$, e o custo total da propriedade.

Com os resultados das atividades desenvolvidas nos sistemas de produção, foi possível calcular os resultados da propriedade segmentados em: custo variável, custo fixo, custo total, receita bruta, margem bruta e margem líquida; o que permitiu o cálculo da rentabilidade do patrimônio, por meio da determinação do valor presente líquido (VPL), a $6 \%$ ao ano, e da taxa interna de retorno (TIR), conforme Peres et al. (2008). Mais especificamente, foram comparados os sistemas de produção quanto aos custos, às margens e à rentabilidade do capital imobilizado. Esta comparação foi feita quando a área foi ocupada no inverno com a

Tabela 1. Atividades desenvolvidas e indicadores técnicos nos sistemas de integração lavoura-pecuária (ILP) e agrícola convencional, para uma propriedade de 100 ha.

\begin{tabular}{|c|c|c|c|c|c|c|}
\hline \multirow[t]{2}{*}{ Item } & \multirow{2}{*}{$\begin{array}{l}\text { Período/ } \\
\text { Medida }\end{array}$} & \multicolumn{4}{|c|}{ Sistemas de ILP - tratamentos ${ }^{(1)}$} & \multirow{2}{*}{$\begin{array}{l}\text { Sistema agrícola } \\
\text { convencional }\end{array}$} \\
\hline & & ALD & APD & ALP & APP & \\
\hline \multicolumn{7}{|l|}{ Atividades } \\
\hline Soja (ha) & Verão & 46,7 & 46,7 & 46,7 & 46,7 & 66,7 \\
\hline Milho (ha) & Verão & 23,3 & 23,3 & 23,3 & 23,3 & 33,3 \\
\hline Trigo (ha) & Inverno & - & - & - & - & 33,3 \\
\hline Novilhas (UBA) & UBA & 156 & 178 & 132 & 174 & - \\
\hline Pastagem perene verão (ha) & Verão & 30 & 30 & 30 & 30 & - \\
\hline Pastagem anual inverno (ha) & Inverno & 70 & 70 & 70 & 70 & - \\
\hline Plantas de cobertura de solo (ha) & Inverno & - & - & - & - & 66,7 \\
\hline \multicolumn{7}{|l|}{ Indicadores técnicos } \\
\hline Produtividade média de soja ${ }^{(2)}$ & $\mathrm{kg} \mathrm{ha}^{-1}$ & 3.738 & 3.526 & 3.862 & 3.895 & 3.775 \\
\hline Produtividade média de milho(2) & $\mathrm{kg} \mathrm{ha}^{-1}$ & 8.112 & 8.133 & 8.112 & 7.305 & 6.894 \\
\hline Produtividade média de trigo ${ }^{(4)}$ & $\mathrm{kg} \mathrm{ha}^{-1}$ & - & - & - & - & 2.740 \\
\hline Peso de entrada das novilhas ${ }^{(3)}$ & $\mathrm{kg}$ de peso vivo & 192,0 & 278,0 & 192,0 & 278,0 & - \\
\hline Peso de saída das novilhas ${ }^{(3)}$ & $\mathrm{kg}$ de peso vivo por dia & 312,0 & 395,0 & 330,0 & 419,0 & - \\
\hline Fase de recria (pastagem de inverno) & $\mathrm{kg}$ de peso vivo & 150 & 150 & 150 & 150 & - \\
\hline Ganho de peso total /animal & $\mathrm{kg}$ por cabeça por dia & 120,0 & 117,0 & 138,0 & 141,0 & - \\
\hline Ganho médio diário(3) & $\mathrm{kg} \mathrm{ha}^{-1}$ por dia & 0,80 & 0,78 & 0,92 & 0,94 & - \\
\hline Carga animal $^{(3)}$ & UBA ha-1 & 1.003 & 1.145 & 849 & 1.122 & - \\
\hline Lotação na pastagem (inverno) ${ }^{(3)}$ & UBA & 2,22 & 2,54 & 1,88 & 2,49 & - \\
\hline Total de animais & - & 156 & 178 & 132 & 174 & - \\
\hline
\end{tabular}


cultura do trigo ou a da aveia para cobertura de solo, e com pastagem anual de inverno para recria de novilhas leiteiras. No verão, considerou-se o cultivo de milho ou soja, em rotação de culturas no sistema de integração lavoura-pecuária.

O custo variável foi calculado ao se considerar: insumos, mão de obra temporária, conservação e reparos de máquinas, implementos e benfeitorias, combustível, frete externo, taxas de recepção, secagem e limpeza, impostos variáveis, assistência técnica, seguros de produção, juros sobre o capital de giro e despesas gerais. Para o cálculo do custo fixo, foram considerados valores de depreciação do capital imobilizado, impostos fixos, mão de obra permanente, seguro sobre o capital fixo, juros sobre o capital fixo e remuneração ao produtor. O custo total de produção foi obtido com a soma dos custos variável e fixo.

A receita bruta foi calculada tendo-se considerado o valor de venda dos produtos multiplicado pela respectiva quantidade vendida. A margem bruta foi o resultado da receita bruta obtida na exploração considerada, menos o custo variável da atividade e a margem líquida definida por meio da diferença entre a receita bruta e o custo total. Uma vez que os custos oportunidade foram incorporados no custo total, a margem líquida positiva é indicativo de que a opção do produtor em alocar seus recursos na atividade agropecuária propicia maior retorno que o uso alternativo do recurso (Hoffmann et al., 1984).

Para o cálculo da receita originada das novilhas leiteiras, foi considerado o preço médio das novilhas comercializadas na unidade de produção de novilhas da Cooperativa Agropecuária Castrolanda, para animais com 24 meses de idade e com prenhez confirmada. Foram calculados os valores em $\mathrm{R} \$ \mathrm{ha}^{-1}$ por ano de recria, tendo-se considerado os indicadores técnicos utilizados (Tabela 1).

Para a análise da viabilidade econômica a longo prazo, utilizou-se a metodologia proposta por Peres et al. (2008), com a elaboração de fluxo de receitas líquidas das atividades avaliadas com a determinação do VPL. A análise de viabilidade de implantação da tecnologia proposta (sistemas de ILP) foi realizada por meio da elaboração de fluxos de caixa incrementais, ou seja, fluxos de caixa referentes ao projeto, que foram obtidos pela diferença entre os saldos dos fluxos de caixa dos sistemas propostos (ILP) e o saldo do fluxo de caixa do empreendimento sem o projeto (sistema agrícola). Assim, a avaliação econômica consistiu no cálculo do VPL do saldo do fluxo de caixa referente ao projeto, que resultou em um valor monetário (em reais) que poderia ser negativo, positivo, ou igual a zero. De acordo com Peres et al. (2008), um projeto pode ser aceito ou implementado quando este VPL for positivo.

\section{Resultados e Discussão}

Os tratamentos utilizados no sistema de ILP não alteraram o rendimento de grãos de soja, mas a ILP aumentou o rendimento de milho em comparação ao sistema convencional simulado (Tabela 1). Silva et al. (2012) registraram os rendimentos dessas culturas com ou sem o uso da ILP.

O capital imobilizado total foi de R\$ 119.654,00, maior para o sistema de ILP, em razão dos investimentos realizados para a formação da pastagem perene de verão e para as benfeitorias e os implementos utilizados exclusivamente com a atividade pecuária (Tabela 2). Lazzarotto et al. (2010) observaram necessidade de investimentos $33 \%$ maiores para o sistema de ILP, em comparação ao sistema agrícola convencional, e destacaram que devem ser feitas inversões em bens específicos para explorar a atividade pecuária.

A cultura da soja apresentou margens líquidas satisfatórias com média de $\mathrm{R} \$ 514,27 \mathrm{ha}^{-1}$ no sistema de ILP e de R\$ 630,65 ha ${ }^{-1}$ no sistema agrícola convencional (Tabela 3). O milho apresentou margens líquidas negativas tanto para o sistema de ILP quanto para o sistema agrícola convencional, com médias de $\mathrm{R} \$ 539,04 \mathrm{ha}^{-1}$ para o sistema de ILP e de R \$ 711,80 hapara o sistema agrícola. O tratamento APP do sistema de ILP e o sistema agrícola convencional apresentaram margens líquidas negativas maiores - de $\mathrm{R} \$ 706,18$ ha $^{-1}$ e R $\$ 711,80$ ha $^{-1}$, respectivamente - , o que pode ser atribuído às menores produtividades obtidas nestes tratamentos, de $7.305 \mathrm{~kg} \mathrm{ha}^{-1}$, no tratamento APP, e de $6.894 \mathrm{~kg} \mathrm{ha}^{-1}$, no sistema agrícola convencional (Tabela 1).

A cultura do trigo, mesmo com produtividade elevada, de $2.740 \mathrm{~kg} \mathrm{ha}^{-1}$, apresentou margem bruta negativa de $\mathrm{R} \$ 145,59 \mathrm{ha}^{-1}$ e margem líquida negativa de R $\$ 851,07$ ha $^{-1}$, o que não cobriu o custo variável para a produção da lavoura. Resultados semelhantes foram obtidos por Molin (2008), em análise econômica do subsistema de produção trigo/soja, no período de 1989 a 2004, ao explorar $100 \%$ da área de inverno com trigo. 
A pastagem anual de inverno, no sistema de ILP, apresentou margem líquida negativa média de $\mathrm{R} \$ 1.003,89 \mathrm{ha}^{-1}$, pois a receita da pastagem foi lançada para a atividade de novilhas leiteiras (24 meses). Já a margem líquida da cultura da aveia utilizada como cobertura de solo no sistema agrícola convencional, foi negativa de $\mathrm{R} \$ 446,48 \mathrm{ha}^{-1}$ (Tabela 3 ), uma vez que, no sistema de ILP, a pastagem anual de inverno foi cultivada com alta tecnologia, com uso de sementes melhoradas e fertilização necessária para elevadas produtividades de matéria seca. Porém, na aveia cultivada para cobertura de solo, o uso de tecnologia foi baixo, tendo-se utilizado, basicamente, as sementes e os serviços necessários para a implantação.

O cultivo da aveia-preta como cobertura de solo, apesar de não apresentar receitas, apenas custos, traz vários benefícios ao sistema de plantio direto. Em áreas essencialmente agrícolas, é importante para a manutenção do solo coberto durante o inverno, o que evita que ocorra erosão e infestação de plantas daninhas. Esta prática permite a redução de gastos com adubo e herbicida, bem como a preservação dos recursos naturais (Machado, 2000).

A atividade de ILP (com novilhas leiteiras) resultou em margem líquida média de $\mathrm{R} \$ 1.364,13 \mathrm{ha}^{-1}$ (Tabela 3), tendo compensando a área que deixou de ser semeada com o trigo e os custos de implantação das pastagens anuais de inverno. Durante o período de inverno, as pastagens (diversificadas ou puras) foram utilizadas para pastejo contínuo, com adequadas estratégias de manejo. Essas pastagens proporcionaram ganho médio diário adequado para

Tabela 2. Composição do capital imobilizado total em terra, máquinas, implementos, benfeitorias e pastagens perenes inventário da propriedade (R\$) -, nos sistemas agrícola convencional e de integração lavoura-pecuária (ILP).

\begin{tabular}{|c|c|c|c|c|c|}
\hline \multirow[t]{2}{*}{ Itens de investimento } & \multicolumn{4}{|c|}{ Sistemas de ILP ${ }^{(1)}$} & \multirow{2}{*}{$\begin{array}{l}\text { Sistema agrícola } \\
\text { convencional }\end{array}$} \\
\hline & ALD & APD & ALP & APP & \\
\hline \multicolumn{6}{|l|}{ 1. Terras } \\
\hline Área da propriedade (ha) & 120,0 & 120,0 & 120,0 & 120,0 & 120,0 \\
\hline Área total cultivada (ha) & 100,0 & 100,0 & 100,0 & 100,0 & 100,0 \\
\hline Área soja - verão (ha) & 46,7 & 46,7 & 46,7 & 46,7 & 66,7 \\
\hline Área milho - verão (ha) & 23,3 & 23,3 & 23,3 & 23,3 & 33,3 \\
\hline Área capim Tifton 85 - verão (ha) & 30,0 & 30,0 & 30,0 & 30,0 & 0,0 \\
\hline Área trigo - inverno (ha) & 0,0 & 0,0 & 0,0 & 0,0 & 33,3 \\
\hline Área pastagem anual inverno (ha) & 70,0 & 70,0 & 70,0 & 70,0 & 66,7 \\
\hline Valor total da terra & $1.487 .632,80$ & $1.487 .632,80$ & $1.487 .632,80$ & $1.487 .632,80$ & $1.487 .632,80$ \\
\hline 2. Máquinas & & & Valor inicial (R\$) & & \\
\hline 1 Trator $(85 \mathrm{CV})(4 \mathrm{x} 4)$ & $103.288,00$ & $103.288,00$ & $103.288,00$ & $103.288,00$ & $103.288,00$ \\
\hline \multicolumn{6}{|l|}{ 3. Implementos } \\
\hline 1 Semeadora 21 linhas - PD & $84.225,00$ & $84.225,00$ & $84.225,00$ & $84.225,00$ & $84.225,00$ \\
\hline 1 Pulverizador barras - 20001 & $51.750,00$ & $51.750,00$ & $51.750,00$ & $51.750,00$ & $51.750,00$ \\
\hline 1 Carreta $(4.000 \mathrm{~kg})$ & $5.733,00$ & $5.733,00$ & $5.733,00$ & $5.733,00$ & $5.733,00$ \\
\hline 1 Carreta tanque 20001 & $5.064,50$ & $5.064,50$ & $5.064,50$ & $5.064,50$ & $5.064,50$ \\
\hline 1 Distribuidor hidráulico $600 \mathrm{~kg}$ & $3.350,00$ & $3.350,00$ & $3.350,00$ & $3.350,00$ & $3.350,00$ \\
\hline 1 Semeadora de milho 8 linhas-PD & $5.064,50$ & $5.064,50$ & $5.064,50$ & $5.064,50$ & $5.064,50$ \\
\hline 1 Roçadeira agrícola & $1.982,00$ & $1.982,00$ & $1.982,00$ & $1.982,00$ & - \\
\hline 1 Botijão de sêmen & $1.990,00$ & $1.990,00$ & $1.990,00$ & $1.990,00$ & - \\
\hline \multicolumn{6}{|l|}{ 4. Benfeitorias } \\
\hline 1 Galpão $200 \mathrm{~m}^{2}$ & $38.900,00$ & $38.900,00$ & $38.900,00$ & $38.900,00$ & $38.900,00$ \\
\hline 2 Casas de empregados $\left(50 \mathrm{~m}^{2}\right)$ & $35.417,00$ & $35.417,00$ & $35.417,00$ & $35.417,00$ & $35.417,00$ \\
\hline 1 Casa sede $150 \mathrm{~m}^{2}$ & $71.125,50$ & $71.125,50$ & $71.125,50$ & $71.125,50$ & $71.125,50$ \\
\hline 1 Centro de manejo $\left(500 \mathrm{~m}^{2}\right)$ & $50.000,00$ & $50.000,00$ & $50.000,00$ & $50.000,00$ & - \\
\hline 1 Balança eletrônica & $7.233,00$ & $7.233,00$ & $7.233,00$ & $7.233,00$ & - \\
\hline 2 Silos metálicos 6 toneladas & $5.000,00$ & $5.000,00$ & $5.000,00$ & $5.000,00$ & - \\
\hline 1 Cerca eletrificada & $10.000,00$ & $10.000,00$ & $10.000,00$ & $10.000,00$ & - \\
\hline 1 Cerca convencional & $15.000,00$ & $15.000,00$ & $15.000,00$ & $15.000,00$ & - \\
\hline \multicolumn{6}{|l|}{ 4. Pastagens perenes } \\
\hline 30 ha de Tifton 85 & $28.449,00$ & $28.449,00$ & $28.449,00$ & $28.449,00$ & - \\
\hline Capital imobilizado total & $2.011 .204,30$ & $2.011 .204,30$ & $2.011 .204,30$ & $2.011 .204,30$ & $1.891 .550,30$ \\
\hline
\end{tabular}

${ }^{(1)} \mathrm{ALD}$, pastagens diversificadas (aveia-preta, azevém anual, trevo-branco e trevo-vermelho) submetidas ao pastejo por animais leves (192 $\pm 40,9 \mathrm{~kg}$ ); APD, pastagens diversificadas submetidas ao pastejo por animais pesados (278 $\pm 41,2 \mathrm{~kg}$ ); ALP, pastagens puras (azevém anual) submetidas ao pastejo por animais leves; APP, pastagens puras submetidas ao pastejo por animais pesados. PD, plantio direto. 
os animais (leves e pesados) testados. Além disso, proporcionaram fitomassa residual após o pastejo animal acima de $2.700 \mathrm{~kg} \mathrm{ha}^{-1}$ de massa seca, a qual é adequada para o sistema de produção adotado e não prejudica a produtividade das culturas subsequentes (Silva et al., 2012).

Os tratamentos dos sistemas de ILP apresentaram margem líquida média de $\mathrm{R} \$ 36.673,39$, enquanto o sistema agrícola convencional resultou em margem líquida negativa de $\mathrm{R} \$ 39.759,23$ (Tabela 4). Os tratamentos com animais pesados em APD e APP do sistema de ILP apresentaram as maiores rentabilidades, em razão das maiores margens líquidas obtidas com a atividade de recria de novilhas. Catrileo et al. (2003) obtiveram resultados semelhantes, o que confirma a presença dos animais como principal contribuinte econômico em estratégias para maximizar a margem bruta em sistemas de integração lavoura-pecuária.

O sistema APP apresentou a melhor rentabilidade com TIR de 4,8\% (Tabela 4). Os sistemas de ILP apresentaram valores de VPL negativos, o que indica inviabilidade econômica à longo prazo, com juros de $6 \%$ ao ano. No entanto, estes sistemas apresentaram melhores rentabilidades quando comparados ao sistema agrícola, com TIR de 1,8\%.

Tabela 3. Composição dos custos totais de produção e resultados das atividades que compõem os sistemas de produção $\left(\mathrm{R} \$\right.$ ha $\left.^{-1}\right)$ nos sistemas agrícola convencional e de integração lavoura-pecuária (ILP).

\begin{tabular}{|c|c|c|c|c|c|}
\hline \multirow[t]{2}{*}{ Discriminação } & \multicolumn{4}{|c|}{ Sistemas de ILP(1) } & \multirow{2}{*}{$\begin{array}{c}\text { Sistema agrícola } \\
\text { convencional }\end{array}$} \\
\hline & ALD & $\mathrm{APD}$ & ALP & APP & \\
\hline Soja - produtividade $\left(\mathrm{kg} \mathrm{ha}^{-1}\right)$ & 3.738 & 3.526 & 3.862 & 3.895 & 3.775 \\
\hline Custo variável & $1.198,71$ & $1.188,12$ & $1.204,87$ & $1.206,51$ & $1.199,23$ \\
\hline Custo fixo & 808,26 & 808,26 & 808,26 & 808,26 & 705,39 \\
\hline Custo total & $2.006,97$ & $1.996,38$ & $2.013,13$ & $2.014,77$ & $1.904,62$ \\
\hline Receita bruta & $2.510,69$ & $2.368,03$ & $2.593,71$ & $2.615,87$ & $2.535,27$ \\
\hline Margem bruta & $1.311,98$ & $1.179,91$ & $1.388,84$ & $1.409,36$ & $1.336,04$ \\
\hline Margem líquida & 503,75 & 371,65 & 580,58 & 601,10 & 630,65 \\
\hline Milho - produtividade $\left(\mathrm{kg} \mathrm{ha}^{-1}\right)$ & 8.112 & 8.133 & 8.112 & 7.305 & 6.894 \\
\hline Custo variável & $2.183,70$ & $2.184,32$ & $2.183,70$ & $2.156,11$ & $2.141,12$ \\
\hline Custo fixo & 793,00 & 793,00 & 793,00 & 793,00 & 690,13 \\
\hline Custo total & $2.976,70$ & $2.977,32$ & $2.976,70$ & $2.949,11$ & $2.831,25$ \\
\hline Receita bruta & $2.491,74$ & $2.497,27$ & $2.491,74$ & $2.242,93$ & $2.119,45$ \\
\hline Margem bruta & 308,04 & 312,95 & 308,04 & 86,82 & $(21,67)$ \\
\hline Margem líquida & $(484,96)$ & $(480,06)$ & $(484,96)$ & $(706,18)$ & $(711,80)$ \\
\hline Trigo - produtividade $\left(\mathrm{kg} \mathrm{ha}^{-1}\right)$ & & & & & 2.740 \\
\hline Custo variável & - & - & - & - & $1.505,35$ \\
\hline Custo fixo & - & - & - & - & 705,48 \\
\hline Custo total & - & - & - & - & $2.210,83$ \\
\hline Receita bruta & - & - & - & - & $1.359,76$ \\
\hline Margem bruta & - & - & - & - & $(145,59)$ \\
\hline Margem líquida & - & - & - & - & $(851,07)$ \\
\hline Pastagem anual de inverno & \multicolumn{2}{|c|}{ Azevém+Aveia+Trevos } & \multicolumn{2}{|c|}{ Azevém anual } & Aveia cobertura \\
\hline Custo variável & 760,27 & 760,27 & 724,27 & 724,27 & 217,98 \\
\hline Custo fixo & 261,62 & 261,62 & 261,62 & 261,62 & 228,50 \\
\hline Custo total & $1.021,89$ & $1.021,89$ & 985,89 & 985,89 & 446,48 \\
\hline Margem bruta & $(760,27)$ & $(760,27)$ & $(724,27)$ & $(724,27)$ & $(217,98)$ \\
\hline Margem líquida & $(1.021,89)$ & $(1.021,89)$ & $(985,89)$ & $(985,89)$ & $(446,48)$ \\
\hline \multicolumn{6}{|l|}{ Novilhas leiteiras (24 meses) } \\
\hline Custo variável & $1.903,42$ & $2.172,89$ & $1.611,17$ & $2.129,24$ & - \\
\hline Custo fixo & 259,81 & 296,59 & 219,92 & 290,64 & - \\
\hline Custo total & $2.163,23$ & $2.469,49$ & $1.831,09$ & $2.419,88$ & - \\
\hline Receita bruta & $3.491,92$ & $3.986,29$ & $2.955,77$ & $3.906,22$ & - \\
\hline Margem bruta & $1.588,51$ & $1.813,40$ & $1.344,61$ & $1.776,97$ & - \\
\hline Margem líquida & $1.328,70$ & $1.516,81$ & $1.124,69$ & $1.486,34$ & - \\
\hline
\end{tabular}

${ }^{(1)} \mathrm{ALD}$, pastagens diversificadas (aveia-preta, azevém anual, trevo-branco e trevo-vermelho) submetidas ao pastejo por animais leves (192 $\pm 40,9 \mathrm{~kg})$; APD, pastagens diversificadas submetidas ao pastejo por animais pesados (278 $\pm 41,2 \mathrm{~kg})$; ALP, pastagens puras (azevém anual) submetidas ao pastejo por animais leves; APP, pastagens puras submetidas ao pastejo por animais pesados. 
A estimativa dos saldos da implantação dos sistemas de ILP (Tabela 5) indica que o sistema APP apresentou o melhor fluxo de caixa incremental anual referente ao projeto, de R\$332.643,30, no sexto ano. O VPL com a implantação do projeto (ILP), tendo-se considerado taxa de desconto de $6 \%$ ao ano, é positivo com valores de $\mathrm{R} \$ 103.924,92$ para o sistema ALD, R $\$ 143.972,81$ para o APD, R\$ 58.302,07 para o ALP e R\$ 171.645,84 para o APP, o que é indicativo de que a implantação dos sistemas de ILP é viável, quando comparados ao sistema agrícola (Tabela 6). Estes valores corroboram os resultados de Lazzarotto et al. (2010), que observaram que os resultados financeiros decorrentes da implantação da ILP são, em comparação aos sistemas agrícola e bovino de corte, menos vulneráveis a variações em fatores operacionais e de mercado, o que propicia os melhores resultados financeiros.

Segundo Fontaneli et al. (2000) e Ambrosi et al. (2001), a ILP sob sistema de cultivo plantio direto é viável tanto para as culturas de inverno e de verão, quanto para a engorda de bovinos, no período invernal. Análises realizadas por Lazzarotto et al. (2009), ao avaliar a volatilidade dos retornos econômicos associados à ILP no Estado do Paraná, indicaram que, a curto prazo, a ILP tende a gerar melhores resultados econômicos que os demais sistemas analisados (especialização na bovinocultura de corte e produção de grãos), e que a combinação de atividades agrícolas e de pecuária pode trazer vantagens interessantes, como a redução na relação risco/retorno esperados.

Tabela 4. Custos, receitas, margens dos sistemas de produção, valor presente líquido ( $\mathrm{R} \$, 6 \%$ ao ano) e taxa interna de retorno (TIR) (\%) nos sistemas agrícola convencional e de integração lavoura-pecuária (ILP), para uma propriedade de 100 ha.

\begin{tabular}{|c|c|c|c|c|c|}
\hline \multirow[t]{2}{*}{ Discriminação } & \multicolumn{4}{|c|}{ Sistemas de ILP IL $^{(1)}$} & \multirow{2}{*}{$\begin{array}{c}\text { Sistema agrícola } \\
\text { convencional }\end{array}$} \\
\hline & ALD & APD & ALP & APP & \\
\hline Custo variável (R\$) & $293.317,94$ & $311.701,20$ & $270.628,17$ & $306.327,38$ & $215.955,36$ \\
\hline Custo fixo (R\$) & $92.722,77$ & $95.297,56$ & $89.930,39$ & $94.880,52$ & $108.764,28$ \\
\hline Custo total (R\$) & $386.040,72$ & $406.998,76$ & $360.558,56$ & $401.207,90$ & $324.719,63$ \\
\hline Receita bruta (R\$) & $419.741,23$ & $447.813,63$ & $386.087,84$ & $447.856,83$ & $284.960,40$ \\
\hline Margem bruta $(\mathrm{R} \$)$ & $126.423,28$ & $136.112,43$ & $115.459,67$ & $141.529,44$ & $69.005,04$ \\
\hline Margem líquida (R\$) & $33.700,51$ & $40.814,87$ & $25.529,27$ & $46.648,92$ & $(39.759,23)$ \\
\hline VPL a $6 \%$ ao ano & $(199.318,03)$ & $(159.270,15)$ & $(244.940,88)$ & $(131.597,11)$ & $(374.737,21)$ \\
\hline TIR (\%) & 4,1 & 4,5 & 3,6 & 4,8 & 1,8 \\
\hline
\end{tabular}

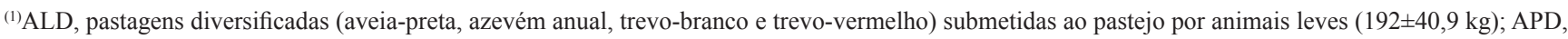
pastagens diversificadas submetidas ao pastejo por animais pesados (278 $\pm 41,2 \mathrm{~kg}$ ); ALP, pastagens puras (azevém anual) submetidas ao pastejo por animais leves; APP, pastagens puras submetidas ao pastejo por animais pesados. VPL, valor presente líquido; TIR, taxa interna de retorno.

Tabela 5. Estimativa dos saldos referentes à implantação dos sistemas de integração lavoura-pecuária, ALD, APD, ALP e APP (em R\$), para uma propriedade de 100 ha, nos sistemas agrícola convencional e de integração lavoura-pecuária (ILP) ${ }^{(1)}$.

\begin{tabular}{|c|c|c|c|c|c|c|c|}
\hline \multirow[t]{2}{*}{ Saldo } & \multicolumn{7}{|c|}{ Ano } \\
\hline & 0 & 1 & 2 & 3 & 4 & 5 & 6 \\
\hline Saldo anual com o projeto ALD & $(2.193 .808)$ & 120.350 & 120.350 & 120.350 & 120.350 & 120.350 & 2.110 .092 \\
\hline Saldo anual no sistema agrícola & $(1.891 .550)$ & 73.343 & 73.343 & 73.343 & 73.343 & 73.343 & 1.814 .795 \\
\hline Saldo anual referente ao projeto ALD & $(302.258)$ & 47.007 & 47.007 & 47.007 & 47.007 & 47.007 & 295.297 \\
\hline Saldo anual com o projeto APD & $(2.219 .560)$ & 130.039 & 130.039 & 130.039 & 130.039 & 130.039 & 2.145 .533 \\
\hline Saldo anual no sistema agrícola & $(1.891 .550)$ & 73.343 & 73.343 & 73.343 & 73.343 & 73.343 & 1.814 .795 \\
\hline Saldo anual referente ao projeto APD & $(328.010)$ & 56.696 & 56.696 & 56.696 & 56.696 & 56.696 & 330.738 \\
\hline Saldo anual com o projeto ALP & $(2.165 .715)$ & 109.386 & 109.386 & 109.386 & 109.386 & 109.386 & 2.071 .035 \\
\hline Saldo anual no sistema agrícola & $(1.891 .550)$ & 73.343 & 73.343 & 73.343 & 73.343 & 73.343 & 1.814 .795 \\
\hline Saldo anual referente ao projeto ALP & $(274.165)$ & 36.043 & 36.043 & 36.043 & 36.043 & 36.043 & 256.240 \\
\hline Saldo anual com o projeto APP & $(2.216 .048)$ & 135.456 & 135.456 & 135.456 & 135.456 & 135.456 & 2.147 .438 \\
\hline Saldo anual no sistema agrícola & $(1.891 .550)$ & 73.343 & 73.343 & 73.343 & 73.343 & 73.343 & 1.814 .795 \\
\hline Saldo anual referente ao projeto APP & $(324.498)$ & 62.113 & 62.113 & 62.113 & 62.113 & 62.113 & 332.643 \\
\hline
\end{tabular}

${ }^{(1)} \mathrm{ALD}$, pastagens diversificadas (aveia-preta, azevém anual, trevo-branco e trevo-vermelho) submetidas ao pastejo por animais leves (192 $\left.\pm 40,9 \mathrm{~kg}\right)$; APD, pastagens diversificadas submetidas ao pastejo por animais pesados (278 $\pm 41,2 \mathrm{~kg}$ ); ALP, pastagens puras (azevém anual) submetidas ao pastejo por animais leves; APP, pastagens puras submetidas ao pastejo por animais pesados. 
Tabela 6. Saldo real referente à implantação dos sistemas de integração lavoura-pecuária, ALD, APD, ALP e APP (em R\$), valor presente líquido (VPL) a $6 \%$ ao ano e taxa de retorno de Fischer (TRF), para uma propriedade de $100 \mathrm{ha}^{(1)}$.

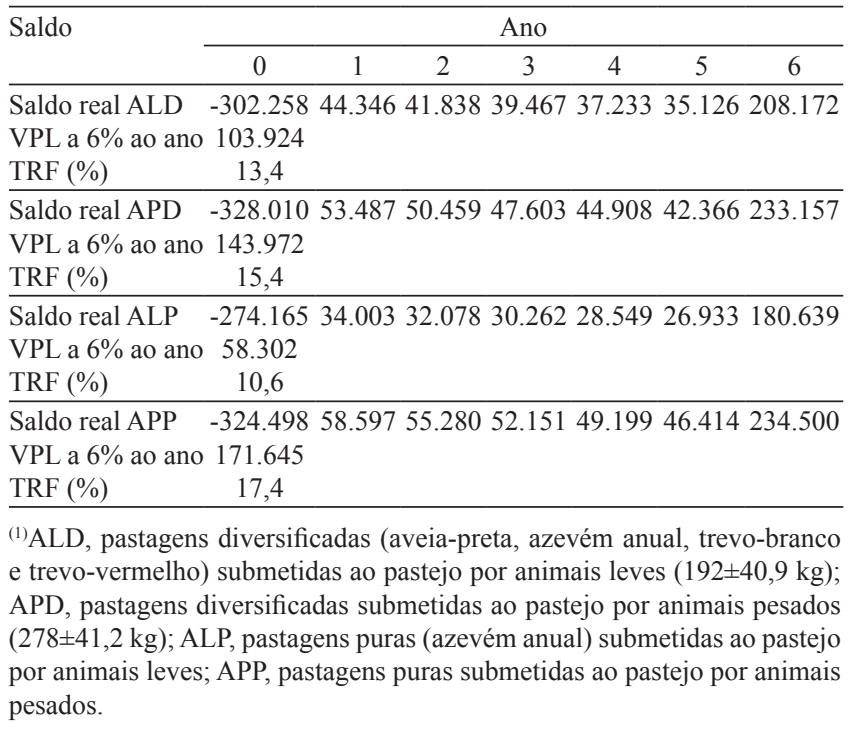

\section{Conclusões}

1. Os tratamentos compostos por pastagens diversificadas submetidas ao pastejo por animais pesados e por pastagens puras submetidas ao pastejo por animais pesados do sistema de integração lavoura-pecuária apresentam os melhores resultados econômicos.

2. O sistema de integração lavoura-pecuária com a recria de novilhas leiteiras em pastagens anuais de inverno, em substituição ao cultivo de cereais de inverno e culturas de cobertura de solo, é a alternativa mais rentável aos produtores.

\section{Referências}

AMBROSI, I.; SANTOS, H.P. dos; FONTANELI, R.S.; ZOLDAN, S.M. Lucratividade e risco de sistemas de produção de grãos combinados com pastagens de inverno. Pesquisa Agropecuária Brasileira, v.36, p.1213-1219, 2001.

ASSMANN, A.L.; PELISSARI, A.; MORAES, A.; ASSMANN, T.S.; OLIVEIRA, E.B. de; SANDINI, I. Produção de gado de corte e acúmulo de matéria seca em sistema de integração lavoura-pecuária em presença e ausência de trevo branco e nitrogênio. Revista Brasileira de Zootecnia, v.33, p.37-44, 2004.

BALBINOT JUNIOR, A.A.; MORAES, A. de; VEIGA, M.; PELISSARI, A.; DIECKOW, J. Integração lavoura-pecuária: intensificação de uso de áreas agrícolas. Ciência Rural, v.39, p.1925-1933, 2009.
CARTAS climáticas do Estado do Paraná - 1994. Londrina: IAPAR, 1994. 49p. (IAPAR. Documentos, 18).

CARVALHO, P.C. de F. O manejo da pastagem como gerador de ambientes pastoris adequados à produção animal. In: SIMPÓSIO SOBRE MANEJO DA PASTAGEM, 22., 2005, Piracicaba. Teoria e prática da produção animal em pastagens: anais. Piracicaba: FEALQ, 2005. p.7-32.

CARVALHO, P.C. de F.; ANGHINONI, I.; MORAES, A. de; TREIN, C.R.; FLORES, J.P.C.; CEPIK, C.T.C.; LEVIEN, R.; LOPES, M.T.; BAGGIO, C.; LANG, C.R.; SULC, R.M.; PELISSARI, A. O estado da arte em integração lavoura e pecuária. In: GOTTSCHALL, C.S.; SILVA, J.L.S.; RODRIGUES, N.C. (Org.). Produção animal: mitos, pesquisa e adoção de tecnologia. Canoas: Ulbra, 2005. p.7-44.

CATRILEO, S.A.; VÉJAR, M.M.; ROJAS, G.C. Estrategias de producción para maximizar el margen bruto en un sistema tradicional ganado-cultivo del secano de la IX región. Agricultura Técnica, v.63, p.240-250, 2003.

CERRI, C.C.; BERNOUX, M.; MAIA, S.M.F.; CERRI, C.E.P.; COSTA JUNIOR, C.; FEIGL, J.; FRAZÃO, L.A.; MELLO, F.F. de C.; GALDOS, M.V.; MOREIRA, C.S.; CARVALHO, J.L.N. Greenhouse gas mitigation options in Brazil for land-use chance, livestock and agriculture. Scientia Agricola, v.67, p.102-116, 2010.

FONTANELI, R.S.; AMBROSI, I.; SANTOS, H.P. dos; IGNACZAK, J.C.; ZOLDAN, S.M. Análise econômica de sistemas de produção de grãos com pastagens anuais de inverno, em sistema plantio direto. Pesquisa Agropecuária Brasileira, v.35, p.2129-2137, 2000.

GUIMARÃES, V.D.A.; PERES, F.C.; CANZIANI, J.R. Avaliação do risco nas culturas de milho, soja e trigo no Paraná. In: CONGRESSO MUNDIAL DE SOCIOLOGIA RURAL, 10.; CONGRESSO BRASILEIRO DE ECONOMIA E SOCIOLOGIA RURAL, 38., 2000, Rio de Janeiro. Anais. Brasília: SOBER: IRSA, 2000. 16p.

HOFFMANN, R.; ENGLER, J.J. de C.; SERRANO, O.; THAME, A.C. de M.; NEVES, E.M. Administração da empresa agrícola. 4.ed. São Paulo: Pioneira, 1984. 325p.

INSTITUTO BRASILEIRO DE GEOGRAFIA E ESTATÍSTICA. Produção da pecuária municipal 2010. Disponível em: <http:// www.ibge.gov.br/home/estatistica/economia/ppm/2010/tabelas pdf/tab23.pdf>. Acesso em: 4 jan. 2012.

LAZZAROTTO, J.J.; SANTOS, M.L. dos; LIMA, J.E. de. Viabilidade financeira e riscos associados à integração lavoura-pecuária no Estado do Paraná. Organizações Rurais e Agroindustriais, v.12, p.113-130, 2010.

LAZZAROTTO, J.J.; SANTOS, M.L. dos; LIMA, J.E. de; MORAES, A. Volatilidade dos retornos econômicos associados à integração lavoura-pecuária no Estado do Paraná. Revista de Economia e Agronegócio, v.7, p.259-284, 2009.

MACHADO, L.A.Z. Aveia: forragem e cobertura do solo. Dourados: Embrapa Agropecuária Oeste, 2000. 16p. (Embrapa Agropecuária Oeste. Coleção sistema plantio direto, 3).

MARCHEZAN, E.; VIZZOTTO, V.R.; ROCHA, M.G. da; MOOJEN, E.L.; SILVA, J.H. da S. Produção animal em várzea 
sistematizada cultivada com forrageiras de estação fria submetidas a diferentes níveis de adubação. Ciência Rural, v.32, p.303-308, 2002.

MOLIN, R. Subsistemas de produção em plantio direto: explorando alternativas econômicas rentáveis para o inverno. Castro: Fundação ABC, 2008. 104p.

PARANÁ (Estado). Secretaria da Agricultura e do Abastecimento. Comparativo de área, produção e produtividade no Paraná nas safras 08/09 e 09/10. 2010. Disponível em: <http://www. agricultura.pr.gov.br/modules/qas/uploads/2135/pssmensal.pdf $>$. Acesso em: 24 jan. 2011.

PERES, F.C.; CANZIANI, J.R.; GUIMARÃES, V.D.A. Programa empreendedor rural: projetos. Curitiba: Serviço Nacional de Aprendizagem Rural, 2008. 264p.

RESTLE, J.; ROSO, C.; SOARES, A.B.; LUPATINI, G.C.; ALVES FILHO, D.C.; BRONDANI, I.L. Produtividade animal e retorno econômico em pastagem de aveia preta mais azevém adubada com fontes de nitrogênio em cobertura. Revista Brasileira de Zootecnia, v.29, p.357-364, 2000.

SILVA, H.A. da; KOEHLER, H.S.; MORAES, A. de; GUIMARÃES, V. Di G.; HACK, E.; CARVALHO, P.C. de F. Análise da viabilidade econômica da produção de leite a pasto e com suplementos na região dos Campos Gerais, Paraná. Ciência Rural, v.38, p.445-450, 2008.

SILVA, H.A. da; MORAES, A. de; CARVALHO, P.C. de F.; DA FONSECA, A.F.; DIAS, T.S. Maize and soybeans production in integrated system under no-tillage with different pasture combinations and animal categories. Revista Ciência Agronômica, v.43, p.757-765, 2012.

SILVA, H.A. da; MORAES, A. de; CARVALHO, P.C. de F.; PONTES, L. da S. Desempenho de novilhas leiteiras em pastagens anuais de inverno sob sistema de integração lavoura-pecuária. Pesquisa Agropecuária Brasileira, v.46, p.1372-1378, 2011.

$\overline{\text { Recebido em } 10 \text { de dezembro de } 2011 \text { e aprovado em } 22 \text { de maio de } 2012}$ 